\section{Editor seeks strong-minded researchers for lively debate ...}

"As always, we welcome your feedback on this issue." Sound familiar? It should - thisisall too often theclosingsentenceofthisjournal'sEditorial. But perhaps we should clarify that it is not merely a space-filler being used in the absence of anything more substantive to say. We do mean it.

The second week of each month, our office becomes that bit more frantic as we work to get the issue finished and off to the printers. Once the piles of journals arrive back, fresh off the press, we wonder what the community will make of the content within its pages. Will they be convinced and excited by the new research being published? What might they think of opinions put forward in the News and Views? Will they agree with our editorial viewpoints? We wait with bated breath but, month after month, very little happens. Noone, it seems, has anything to say. Or, more likely, people have plenty to say but neither the time nor the inclination to put finger to keyboard and tell us about it.

Our Correspondence section has always been intended as a forum for discussion of the content we have recently published, but importantly, also the wider issues in the field. Particularly at this time, with molecular and cellular biology directly impinging on several intricate ethical issues, from stem cells to gene technology, we feel it is imperative that researchers discuss these topics openly with the community. This is particularly true given that researchers are held to more intense public scrutiny these days.

So far, our Correspondence section has been put to limited use, predominantly being used for the publication of refutations. In contrast to some other journals, we think that refutations are a key part of the scientific process, and we are happy to publish these so long as they make a definitive point supported by data that stands up to the usual stringent criteria of this journal. In our mind, there are two types of refutation. The first is when researchers have done almost exactly the same experiment and come to a different conclusion to that published in an NCB paper. On occasion, this may even lead to the retraction of the original paper. The second, which forms the bulk of refutations in our experience, is instances where another group has come to inconsistent conclusions based on their related experiments (for example, using another system or experimental aproach).

In each case, the procedure is this: we give the authors of the original study the option to respond, providing their explanation for the basis of the discrepancy. Both the refutation and the response are then fully peer reviewed, usually by the original reviewers. Should the reviewers find the data or arguments convincing, we may publish the refutation with or without the response in our Correspondence section (see our April 2005 issue for a recent example). As always, each refutation and the response is published, or not, on the basis of its own merit. These are considered to be bona fide publications and, as such, are cited on PubMed. Often, the reason for differing conclusions cannot always be explained fully, but we hope that by publishing the observations, readers can come to their own conclusions and further studies can be instigated to move the field forward.

Beyond refutations, we continue to hope that this section will also provide a means for researchers to write in about whatever is on their mind, be it issues pertinent to cell biology and society, the funding and publishing process, or developing research trends within the field. There are few printed forums that allow ongoing discussions of key issues in cell biology, so we hope you will make use of this one. As always, we welcome ....

\section{EU basic research spending plans take shape}

On 6 April, the European Commission adopted the Seventh Research Framework Programme (FP7), set to run 2007-2013 (http://europa. eu.int/rapid/pressReleasesAction.do). After a significant consultation exercise last year, the thematic priorities of the previous framework programme remain largely unchanged. Although there is a continued emphasis on support for research that is relevant to industry and for trans-European cooperation, two changes stand out. First, the European Research Council (ERC) has finally been given the goahead as an autonomous institution, with the stated aim of enhancing the quality of basic research. Second, there is an explicit emphasis on scientific excellence achieved through competition and peer review. However, this apparent shift to a more merit-based awards policy is dampened by the fact that of the overall budget of almost $€ 68$ billion, only one-fifth ( $€ 10.5$ billion) is earmarked for distribution by the ERC, compared with $€ 39.2$ billion for cooperative research initiatives. Whereas the total budget has doubled, the actual rise is not as pronounced, because the money is spread over seven years, rather than four, as previously. Nevertheless, this extended funding period provides much needed continuity for large multinational research programmes.

Of course, the proposal is yet to be debated by the council of member states and the European Parliament. Although the proposal is likely to pass at parliament level, a concern is that several council members, particularly those facing federal deficits, will erode the budget - either directly, or by reducing domestic research spending. The proposed European research budget represents less than $10 \%$ of R\&D spending within the European Union (or $0.1 \%$ of EU GDP) and it would be lamentable if this programme, which is clearly heading in the right direction on several fronts, had the wind taken out of its sails. To ensure the long-term viability of Europe as a knowledge-based economy, spending on basic research must continue to grow in real terms. 